\title{
A new laboratory method for evaluating formation damage in fractured carbonate reservoirs
}

\author{
Ye Yan${ }^{1}$, Yan Jienian ${ }^{1 *}$, Zou Shengli², Wang Shuqi ${ }^{2}$ and Lu Rende ${ }^{1}$ \\ ${ }^{1}$ Key Laboratory of Petroleum Engineering, Ministry of Education, China University of Petroleum, Beijing 102249, China \\ ${ }^{2}$ Tarim Oilfield Company, PetroChina, Korla, Xinjiang 841000, China
}

\begin{abstract}
Natural carbonate core samples with artificial fractures are often used to evaluate the damage of fractured carbonate formations in the laboratory. It is shown that the most frequent error for evaluation results directly from the random width characterized by the artificial fractures. To solve this problem, a series of simulated fractured core samples made of stainless steel with a given width of fracture were prepared. The relative error for the width of artificial fracture decreased to $1 \%$. The width of natural and artificial fractures in carbonate reservoirs can be estimated by image log data. A series of tests for formation damage were conducted by using the stainless steel simulated core samples flushed with different drilling fluids, such as the sulfonate/polymer drill-in fluid and the solids-free drill-in fluid with or without ideal packing bridging materials. Based on the experimental results using this kind of simulated cores, a novel approach to the damage control of fractured carbonate reservoirs was presented. The effective temporary plugging ring on the end face of the simulated core sample can be observed clearly. The experimental results also show that the stainless steel simulated cores made it possible to visualize the solids and filtrate invasion.
\end{abstract}

Key words: Formation damage, fracture width, image logging, ideal packing, simulated fractured cores

\section{Introduction}

For fractured carbonate reservoirs, there is a significant challenge to identifying and evaluating the potential damage as a result of the reservoir features, such as serious heterogeneity, double porosity media and large naturally occurring or extensive interconnected fractures. Different from most porous sandstones, the matrix permeability in the fractured carbonate reservoir is very low (Al-Taq et al, 2005), in most situations, the high-permeability fractures and vug systems act as conduits or channels for hydrocarbon transfer from a tight producing source matrix to the wellbore for production. This being the case, the preservation of the high-permeability fractures and vugs is of prime importance.

Unfortunately, there is very little work reported in the literature on investigating formation damage in naturally fractured carbonate reservoirs.

Bailey and Boek (1999) stated that solids invasion was much deeper in fractured formations than in sandstone formations due to the presence of fractures. However, the minimum filtrate volume and thereby the minimum indepth penetration could be obtained when properly designed particulates were added into drilling fluids. Thus, designing proper particle-size distribution according to the formation fracture width is a critical issue in formulating a minimally

* Corresponding author. email: yanjienian@sina.com

Received July 23, 2007 invading and low damage drill-in fluid.

The best way to evaluate the potential damage of fractured formations is to test representative field fluids and core samples under simulated downhole conditions, which is possible with accurate width data (Cui and Zhang, 1999). Conventionally, natural carbonate core samples were used (Liu et al, 2006). The samples were pressurized to get a penetrating fracture in the axial direction, and then vacuum saturated with the target formation brine or the brine prepared with its simulated formulation. To match the width of downhole fractures, metallic filaments were frequently deployed and played a role of fracture proppant. However, if the width of fracture is beyond the regime of elastic deformation of filament due to the decrease of confining pressure, the filaments could depart from the fracture and produce minute migration when fluids invaded into the fracture. Consequently, it is difficult to obtain the exact width of the fracture by this way. Moreover, natural samples have a poor repeatability and it is impossible to obtain consistent results and impossible to optimize the selection of bridging particles.

\section{A novel evaluation method for fractured reservoirs}

Recently, a physical interpretation method was developed to describe the characteristics of carbonate rock (Zheng et al, 2004). It is possible to analyze pore configurations quantitatively and examine macroscopic pore connectivity 
and rock permeability. Based on the image log data, the width of downhole fractures can be determined. Stainless steel core samples were prepared to simulate the fractured core. The stainless steel simulated cores can hold a constant simulated fracture width due to a low coefficient of compressibility and so can minimize the experimental error caused by random fracture width, which is inherent in a natural core with an artificial fracture.

\subsection{Stainless steel simulated cores}

A series of stainless steel cores were developed to simulate fractures with different sizes. There were four widths, 40, 50, 70 and $100 \mu \mathrm{m}$, respectively. They are presented in Figs. 1 and 2. The cores had a length of $5.869 \mathrm{~cm}$ and a diameter of $2.510 \mathrm{~cm}$. A uniform fracture with a given width can be obtained as long as the confining pressure is maintained at a given level. It can be similar to the width of a downhole fracture. The simulated cores were split into two parts and can be easily assembled by a slipping operation. This is done to observe the invasion depth of drill-in fluids directly. In addition to the conventional vertical fracture, a fracture with an angle of 30 degrees was also developed.

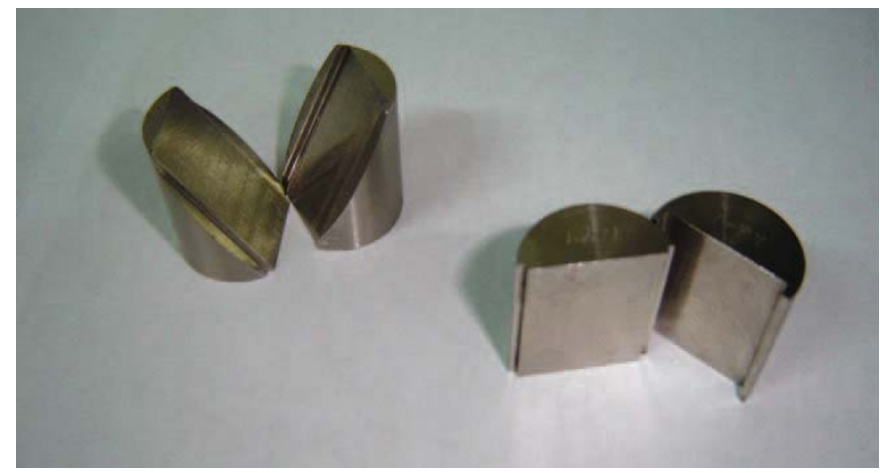

Fig. 1 Simulated fractures with different angles

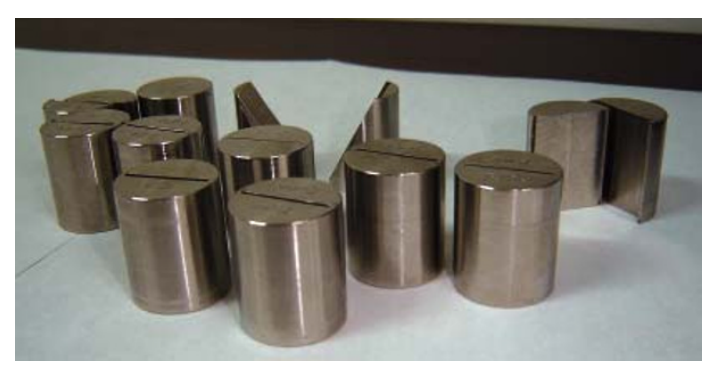

Fig. 2 Stainless steel simulated cores with different fracture widths

\subsection{Applicability of stainless steel simulated core}

A group of tests was conducted to examine the impact of confining pressure on the width of the simulated fracture. The stainless steel core used had a fracture width of about $50 \mu \mathrm{m}$. The effective fracture width reduced only slightly with an increase of the confining pressure from 3 to $8 \mathrm{MPa}$, as shown in Fig. 3.

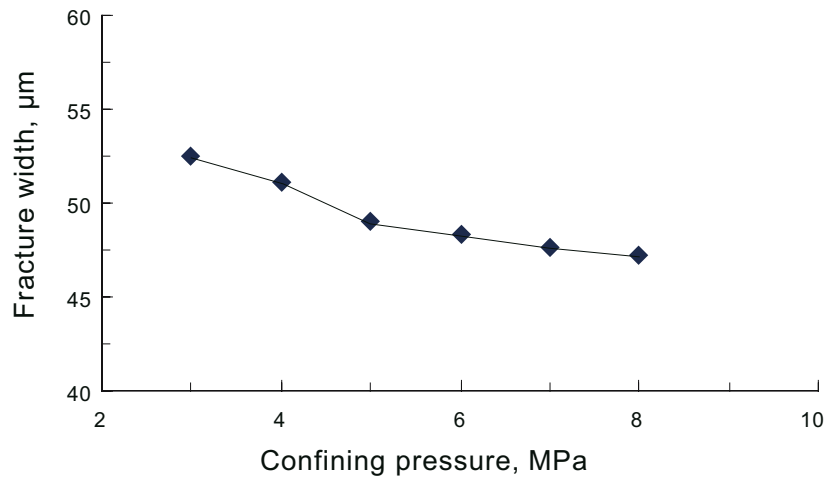

Fig. 3 Effect of confining pressure on the width of the simulated fracture

Another group of tests was conducted to evaluate the effect of confining time on the width of the simulated fracture at a given confining pressure of $6 \mathrm{MPa}$. Kerosene was used as the experimental fluid. The effective widths of the simulated fracture were measured respectively at different confining times, as shown in Fig. 4.

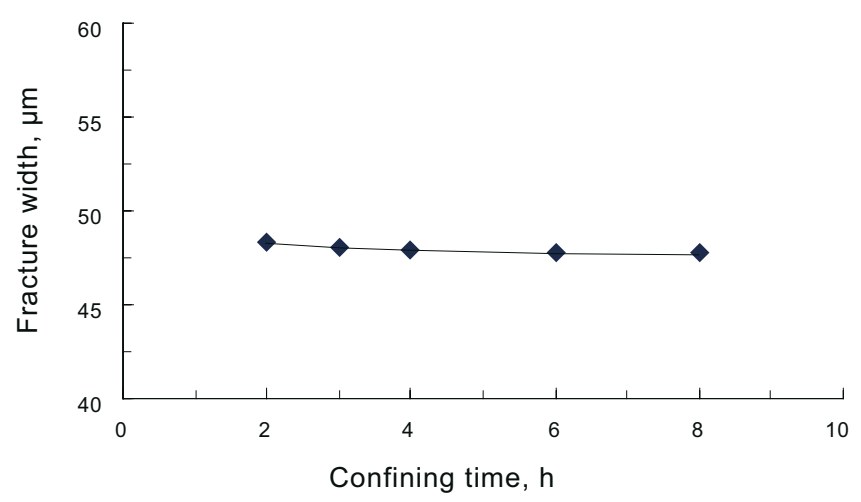

Fig. 4 Effect of confining time on the width of the simulated fracture at a given confining pressure of $6 \mathrm{MPa}$

In this case, the relative error of the width was less than $1 \%$ even if the experimental period of time was more than 8 $\mathrm{h}$ at a constant pressure. The tests indicate that the stainless steel simulated core could guarantee the effectiveness and accuracy of the simulated fracture width. Moreover, the effect of test conditions and properties of testing fluids on the fracture width could be ignored. Therefore, the stainless steel simulated core samples can be used repeatedly.

\section{Calculation of simulated fracture width}

The relevant mathematical model (Salimi and Alikarami, 2006) for the simulated fracture width is established based on the parallel plate theory and Darcy's law, as shown below:

$$
W=2\left[\frac{3}{2} \times \frac{A}{H_{\mathrm{f}}}\left(K_{\mathrm{f}}-K_{\mathrm{m}}\right)\right]^{\frac{1}{3}}
$$

where $K_{\mathrm{f}}$ is the measured permeability, $10^{-3} \mu \mathrm{m}^{2} ; K_{\mathrm{m}}$ is the matrix permeability, $10^{-3} \mathrm{~m}^{2} ; A$ is the cross sectional area of core sample, $\mathrm{cm}^{2} ; W$ is the fracture width, $\mu \mathrm{m} ; H_{\mathrm{f}}$ is the 
fracture height, $\mathrm{cm}$.

Because the permeability of the simulated core is zero, i.e. $K_{\mathrm{m}}=0$, Eq. (1) can be simplified as follows, and be used to calculate the simulated fracture width:

$$
W=2\left[\frac{3}{2} \times \frac{A}{H_{\mathrm{f}}} K_{\mathrm{f}}\right]^{\frac{1}{3}}
$$

The measured permeability is derived from Darcy's law:

$$
K_{\mathrm{f}}=\frac{\mu Q H_{\mathrm{f}}}{A \Delta p}
$$

Substituting Eq. (3) into Eq. (4) gives an equation for calculating the fracture width. The empirical coefficient 5.848 here is used just under specific experimental conditions.

$$
W=5.848\left[\frac{\mu Q}{\Delta p}\right]^{\frac{1}{3}}
$$

where $Q$ is the flow rate, $\mathrm{ml} / \mathrm{min} ; \Delta p$ is the differential pressure, $\mathrm{MPa} ; \mu$ is the fluid viscosity, $\mathrm{mPa} \cdot \mathrm{s}$.

Then the effective permeability of the fractured core was calculated according to Eq. (5)

$$
K_{\mathrm{f}}=\frac{5}{3}\left(\frac{\mu Q H_{\mathrm{f}}}{A \Delta p}\right)
$$

\section{Test procedures of the new evaluation method}

The steel simulated core was mounted inside a rubber sleeve and subjected to confining pressure, a transfer cylinder was used to deliver kerosene or mud to the core holder. A pump, which could deliver fluid at a maximum flow rate of $50 \mathrm{ml} / \mathrm{min}$ and maximum pressure of $26 \mathrm{MPa}$, was connected with the transfer cylinder to deliver the fluids at the desired flow rate and pressure. Differential pressure meters were installed on both side of the core holder to measure differential pressure across the core. The following test procedures were adopted to evaluate the damage induced by drill-in fluids:

1) The stainless steel simulated core sample with a given fracture width was selected according to the image log analysis results.

2) The forward direction of the core was marked firstly, and then the core was mounted into the core holder.

3) Filtrated kerosene was displaced in the forward direction under a constant confining pressure until a steady differential pressure $\Delta p$ was achieved, and then the flow rate $Q$ at this time was recorded; the fracture width was calculated according to Eq. (4), and the effective permeability of the fractured core was calculated according to Eq. (5).

4) The drill-in fluid sample was injected into the fracture in the reverse direction under a constant differential pressure of 3.5 MPa. In this process, the confining pressure was kept constant for $2 \mathrm{~h}$.

5) While the confining pressure was kept unchanged, kerosene was circulated to wash the invaded end of core, direct and reverse washing were performed through two series of lines until the filtrate or particles previously in the drill-in fluid could not be observed in the discharge kerosene.

6) The kerosene was displaced again in the forward direction until a steady state was achieved, the current differential pressure and flow rate were recorded, and the mud cake lift-off pressure was also measured. Then the effective permeability of the fracture after exposure to the drill-in fluid was calculated finally.

7) The return permeability was calculated by the ratio between the effective permeabilities of the fracture before and after exposure to the drill-in fluid.

\section{Damage evaluation for two types of drill-in fluids}

\section{1 Formulations and properties of the tested drill- in fluids}

The image log data can be helpful to describing the characteristics and porosity of rocks, according to these log data, the fracture morphology can be depicted more effectively (Chauveteau et al, 1997). For example, based on the image log data of a drilled well in the Lungu area, the Tarim Oilfield, the number of fractures was figured out, and the frequency distribution of fracture width is presented in Fig. 5. This demonstrates that the width of most fractures were less than $0.1 \mathrm{~mm}$, the maximum contribution was the size of $50-\mu \mathrm{m}$ fractures. Hence, the fracture width of 40-50 $\mu \mathrm{m}$ of the simulated core was selected in the following evaluation tests.

Sulfonate/polymer drill-in fluid and solids-free drillin fluid are commonly used during drilling operations in the Ordovician carbonate formation in the Lungu area. Thus the evaluation experiments were focused on the two types of drill-in fluids, and conducted on the simulated core samples and the artificially fractured carbonate core samples respectively. The formulations of the two types of drill-in fluids are as follows:

1) The solids-free drill-in fluid: Water $+0.1 \% \mathrm{NaOH}+$ $0.5 \%$ CX-216 $+0.2 \%$ FLOWZAN $+2 \%$ SJ $-2+2 \%$ PRD + $7 \% \mathrm{KCl}+\mathrm{NaCl}$ (weighted) $+\mathrm{CaCl}_{2}$ (weighted)

2) The sulfonate/polymer drill-in fluid: $4 \%$ bentonite + $0.2 \% \mathrm{NaOH}+0.5 \%$ CMC-LV $+5 \%$ SMP- $1+3 \%$ SPNH $+3 \%$ XHL $+0.4 \%$ SP- $80+2 \%$ MHR- $86 \mathrm{D}+2 \% \mathrm{NaCl}+$ $\mathrm{CaCO}_{3}$ (weighted)

The properties of these two drill-in fluids are listed in Table 1.

In order to prevent the solids and filtrate in mud from invading into the fractured pay zone, it is of prime importance to optimize the size distribution of the bridging agents in relation to the formation pore openings. The sized bridging particles can develop an excellent mud cake on the formation face to achieve minimum solids and filtrate penetration (Yan and Feng, 2006). The commonly used rigid bridging particles are sized calcium carbonate because it can later be removed very easily by acidization. Furthermore, Di and Sharma (1996) proposed that some kinds of sized fibers are excellent additives for the drill-in fluid to minimize formation damage while drilling fractured formations. In this study, the 


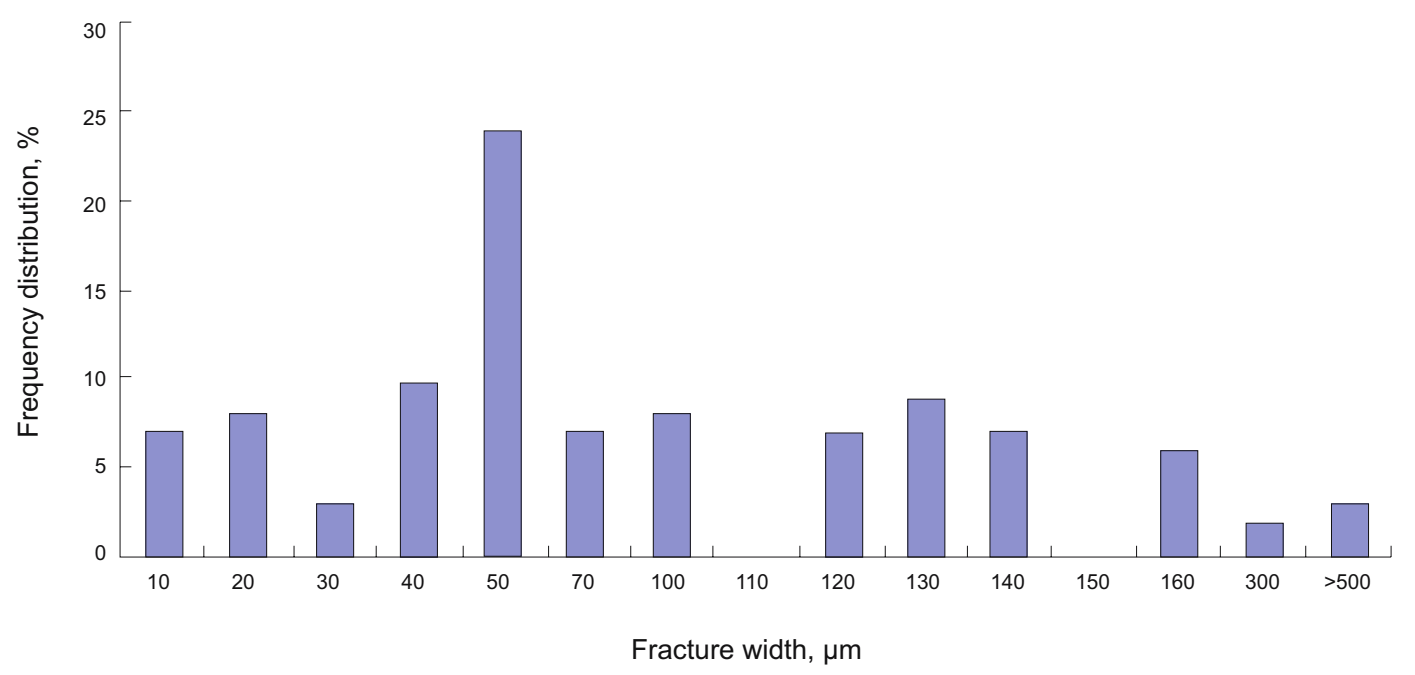

Fig. 5 Frequency distribution of fractures provided by image log data

Table 1 Properties of two drill-in fluids

\begin{tabular}{ccccccccc}
\hline Drill-in fluid type & $\begin{array}{c}\text { Density } \\
\mathrm{g} / \mathrm{cm}^{3}\end{array}$ & $\begin{array}{c}\mathrm{AV} \\
\mathrm{mPa} \cdot \mathrm{s}\end{array}$ & $\begin{array}{c}\mathrm{PV} \\
\mathrm{mPa} \cdot \mathrm{s}\end{array}$ & $\begin{array}{c}\mathrm{YP} \\
\mathrm{Pa}\end{array}$ & $\begin{array}{c}\mathrm{Gel} \\
\mathrm{Pa} / \mathrm{Pa}\end{array}$ & $\begin{array}{c}\mathrm{API}-V_{\mathrm{f}} \\
\mathrm{ml}\end{array}$ & $\begin{array}{c}\mathrm{HTHP}-V_{\mathrm{f}} \\
\mathrm{ml}\end{array}$ & $\mathrm{pH}$ value \\
\hline Sulfonate/polymer & 1.22 & 27 & 19 & 8 & $3 / 10$ & 4.8 & 9.6 & $8-9$ \\
Solids-free & 1.21 & 20 & 11 & 9 & $2 / 3.5$ & 8.6 & 16.2 & $7-8$ \\
\hline
\end{tabular}

Notes: AV- Apparent viscosity; PV- Plastic viscosity; YP- Yield pressure; API- $V_{\mathrm{f}}$ - API filter loss; HTHP- $V_{\mathrm{f}}$ - Filter loss under high temperature and high pressure

sized fibers (DF-1) were used as the other bridging agent in addition to the calcium carbonate with smaller particle size. The software named "optimization tool of ideal packing bridging agents" (Feng and Yan, 2007) was used to determine the bridging particles with optimum particle-size distribution for the Lungu formation. Prior data (Yan, 2001) suggested that $3-5 \%$ by volume of a proper blend of bridging agents can provide an effective sealing on the face of permeable formations. According to the principle of ideal packing, the optimized blending proportion of the ideal-packing agent was determined as follows: $1.6 \% 100-$ mesh $\mathrm{CaCO}_{3}+1.6 \% 300$ -mesh $\mathrm{CaCO}_{3}+0.8 \%$ 800-mesh $\mathrm{CaCO}_{3}+0.5 \%$ DF-1. After mixing ideal-packing sized bridging agents into the sulfonate/ polymer drill-in fluid and solids-free drill-in fluid, another group of comparative experiments were conducted to evaluate the damage level, using the steel simulated cores and the artificially fractured carbonate cores, respectively. The five stainless steel simulated core samples (S1-S5) had a length of $5.869 \mathrm{~cm}$ and a diameter of $2.510 \mathrm{~cm}$. The five artificially fractured carbonate core samples were from different wells in Lungu area and Tazhong area, the Tarim Oilfield, and their parameters are also listed in Table 2.

\subsection{Experimental results and discussion}

Numerous experiments were carried out using the stainless steel simulated core samples under varied conditions. Only the results for four core samples are presented in this paper because the conclusions drawn from other experiments are similar.

5.2.1 Damage evaluation before adding ideal-packing agent

The results of return permeability tests for the sulfonate/ polymer drill-in fluid and the solids-free drill-in fluid before adding optimized ideal-packing agent are shown in Tables 3 and 4 , respectively.

Damage evaluation results indicate that the return permeability values tested with the stainless steel simulated cores were less than those with the artificially fractured carbonate cores when other test conditions are kept the same. Due to the inherent characteristics of the stainless steel cores, it is more difficult to develop an effective mud cake on the edge of stainless steel core than that on the edge of carbonate core. The fracture in the stainless steel simulated core was overall penetrated by the drill-in fluid and some solid particles when the sulfonate/polymer drill-in fluid was used, as shown in Fig. 6. A small quantity of filtrate, however, was observed in the fracture of the stainless steel simulated core when the solids-free drill-in fluid was tested, as shown in Fig. 7. Although it is known that the solids-free drill-in fluid seemed to mitigate the damage to fractured formation more effectively, the return permeability values of both drill-in fluids were very low in this experiment while using the new evaluation method. This indicates that it was essential to add the proper sized bridging materials into the drill-in fluid. This is the case even for the solids-free drill-in fluid. 
Table 2 Parameters of artificially fractured carbonate core samples

\begin{tabular}{|c|c|c|c|c|c|}
\hline $\begin{array}{l}\text { Artificially fractured carbonate } \\
\text { core sample }\end{array}$ & Well name & Well interval & Formation & Length, $\mathrm{cm}$ & Diameter, cm \\
\hline A1 & LG 41-19 & 5571.77 & Ordovician & 3.033 & 2.516 \\
\hline $\mathrm{A} 2, \mathrm{~A} 5$ & TZ 828-88 & 5572.30 & Ordovician & 3.969 & 2.568 \\
\hline $\mathrm{A} 3, \mathrm{~A} 4$ & TZ 828-85 & 5581.22 & Ordovician & 4.063 & 2.559 \\
\hline
\end{tabular}

Table 3 Return permeability of the sulfonate/polymer drill-in fluid before adding ideal-packing agent

\begin{tabular}{|c|c|c|c|c|c|}
\hline Core sample & $\begin{array}{l}\text { Fracture } \\
\text { width, } \mu \mathrm{m}\end{array}$ & $\begin{array}{c}\text { Maximum flowback differential } \\
\text { pressure, } \mathrm{MPa}\end{array}$ & $\begin{array}{l}\text { Filter } \\
\text { loss, ml }\end{array}$ & $\begin{array}{c}\text { Return } \\
\text { permeability, \% }\end{array}$ & $\begin{array}{l}\text { Penetrated } \\
\text { depth, } \mathrm{mm}\end{array}$ \\
\hline $\mathrm{S} 1$ & 48.9 & 2.00 & 2 & 8.5 & Total \\
\hline $\mathrm{S} 2$ & 49.2 & 1.60 & 2 & 12.1 & Total \\
\hline A1 & 50.2 & 1.00 & 3 & 30.8 & 3 \\
\hline $\mathrm{A} 2$ & 52.8 & 0.50 & 3 & 34.6 & $2-3$ \\
\hline
\end{tabular}

Table 4 Return permeability of the solids-free drill-in fluid before adding ideal-packing agent

\begin{tabular}{cccccc}
\hline Core sample & $\begin{array}{c}\text { Fracture } \\
\text { width, } \mu \mathrm{m}\end{array}$ & $\begin{array}{c}\text { Maximum flowback differential } \\
\text { pressure, MPa }\end{array}$ & $\begin{array}{c}\text { Filter } \\
\text { loss, ml }\end{array}$ & $\begin{array}{c}\text { Return } \\
\text { permeability, \% }\end{array}$ & $\begin{array}{c}\text { Penetrated } \\
\text { depth, mm }\end{array}$ \\
\hline S3 & 48.78 & 0.50 & 4.0 & 17.8 & Total \\
A3 & 46.14 & 3.50 & 4.2 & 18.9 & Total \\
\hline
\end{tabular}

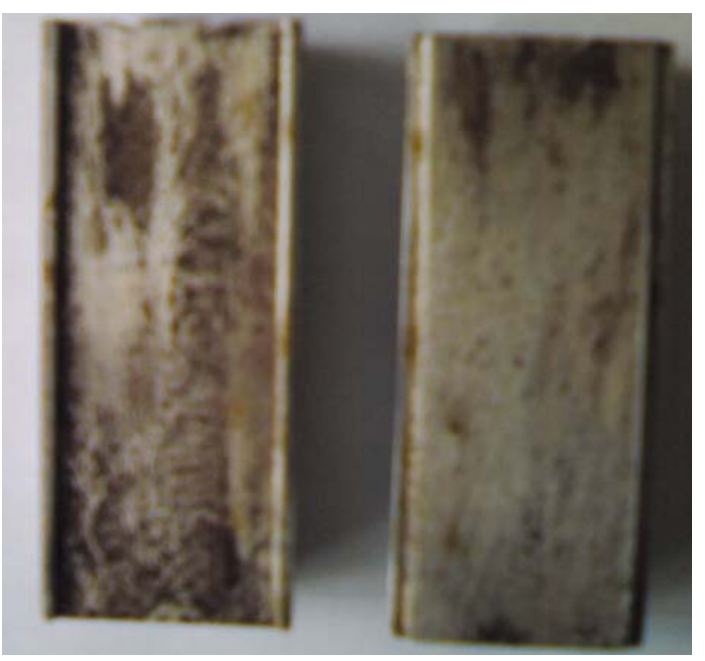

Fig. 6 The core face after exposure to sulfonate/polymer drill-in fluid

\subsubsection{Damage evaluation after adding ideal-packing agent}

Experimental results after adding the optimized idealpacking agent into two types of drill-in fluid are given in

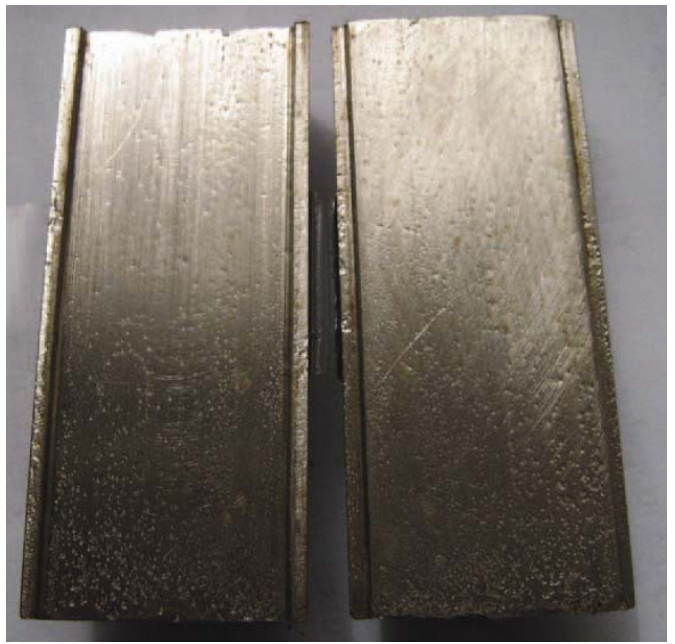

Fig. 7 The core face after exposure to solids-free drill-in fluid

Tables 5 and 6, respectively. After adding the sized idealpacking agent mentioned above, the return permeability of the sulfonate/polymer drill-in fluid increased to $37.6 \%$ and 
Table 5 Return permeability of the sulfonate/ polymer drill-in fluid after adding sized ideal-packing agent

\begin{tabular}{cccccc}
\hline $\begin{array}{c}\text { Core } \\
\text { sample }\end{array}$ & $\begin{array}{c}\text { Fracture } \\
\text { width, } \mu \mathrm{m}\end{array}$ & $\begin{array}{c}\text { Maximum flowback } \\
\text { differential pressure, MPa }\end{array}$ & $\begin{array}{c}\text { Filter } \\
\text { loss, ml }\end{array}$ & $\begin{array}{c}\text { Return } \\
\text { permeability, \% }\end{array}$ & $\begin{array}{c}\text { Penetrated } \\
\text { depth, mm }\end{array}$ \\
\hline S4 & 48.2 & 0.095 & 2.0 & 37.6 & 2 \\
A4 & 51.8 & 0.050 & 1.4 & 75.4 & 1 \\
\hline
\end{tabular}

Table 6 Return permeability of the solids-free drill-in fluid after adding sized ideal-packing agent

\begin{tabular}{cccccc}
\hline $\begin{array}{c}\text { Core } \\
\text { sample }\end{array}$ & $\begin{array}{c}\text { Fracture } \\
\text { width, } \mu \mathrm{m}\end{array}$ & $\begin{array}{c}\text { Maximum flowback } \\
\text { differential pressure, MPa }\end{array}$ & $\begin{array}{c}\text { Filter } \\
\text { loss, ml }\end{array}$ & $\begin{array}{c}\text { Return } \\
\text { permeability, \% }\end{array}$ & $\begin{array}{c}\text { Penetrated } \\
\text { depth, mm }\end{array}$ \\
\hline S5 & 48.01 & 0.07 & 1.8 & 57.3 & 1 \\
A5 & 47.02 & 0.04 & 0.6 & 97.2 & 0 \\
\hline
\end{tabular}

the value of the solids-free drill-in fluid increased to $57.3 \%$ when the new evaluation method was adopted. The return permeability values of both drill-in fluids reached $75 \%$ and $97.2 \%$, and the invaded depth decreased to $1-2 \mathrm{~mm}$ when the conventional evaluation method was adopted. The results indicate that the temporary sealing developed by the solidsfree fluid was more effective than that developed by the sulfonate/polymer fluid after adding the ideal-packing agent.

The photo shown in Fig. 8 indicates that temporary sealing was developed after the ideal-packing agent was added into the sulfonate/polymer drill-in fluid, the invaded depth, however, reached $2 \mathrm{~mm}$ and a few of colloidal particles could be observed on the face of the simulated fracture.

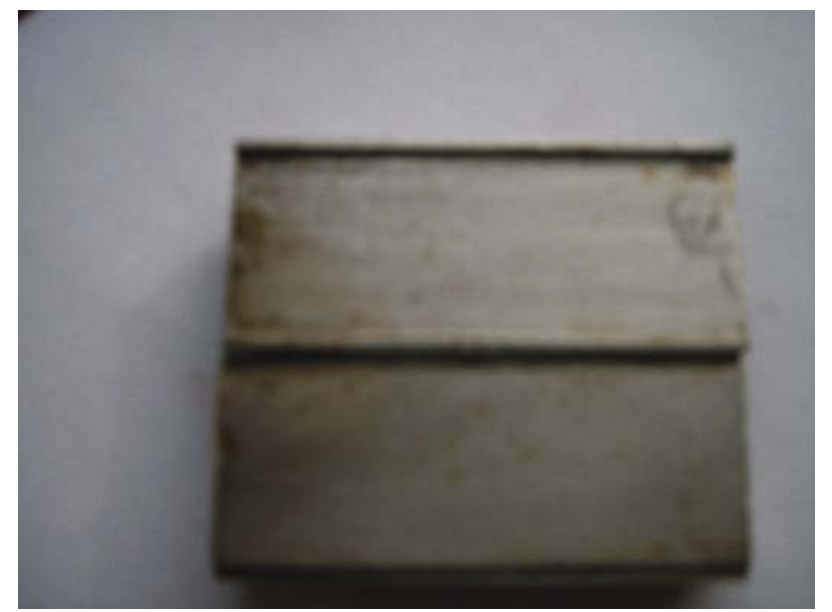

Fig. 8 The simulated core tested with the sulfonate/polymer drill-in fluid after adding ideal-packing agent

The photo shown in Fig. 9 indicates that more effective temporary sealing was generated on the edge of simulated core after adding ideal-packing agent into solids-free drill-in fluid. The return permeability measured with the conventional evaluation method increased to $97.2 \%$ and almost no fluid was present in the fracture in the simulated core. The improvement of return permeability indicates obviously the suitability of the new evaluation method to optimize the sized temporary sealing design. It also manifests the excellent effectiveness of the ideal-packing design employed in the drill-in fluid for fractured formation.

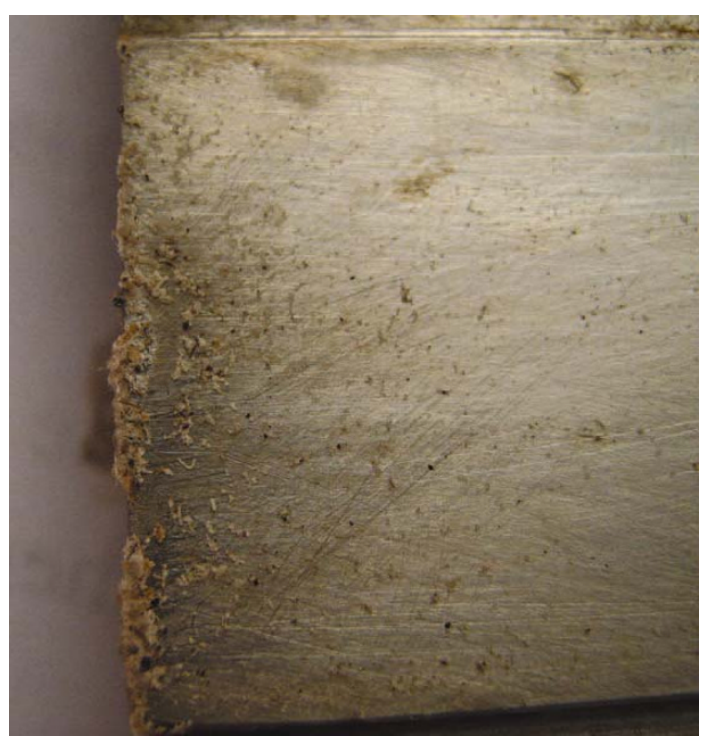

Fig. 9 The simulated core tested with the solids-free drill-in fluid after adding ideal-packing agent

\section{Conclusions}

1) The results of this study confirm that the width of fractures simulated exactly is very important for identifying and quantifying damage prior to drilling operations for fractured formations.

2) Experiments conducted by using the new stainless steel simulated cores can hold a constant simulated fracture 
width, and so can minimize the experimental error caused by random fracture width which is inherent in a natural core with artificial fractures.

3) A new evaluation method for fractured formation damage is developed and the test procedures are also suggested. The fracture width of the stainless steel simulated core is selected based on formation $\log$ data and the calculation equation for the width of simulated fracture is given by

$$
W=5.848 \quad\left[\frac{\mu Q}{\Delta p}\right]^{\frac{1}{3}}
$$

4) For overbalanced drilling in a fractured reservoir, the invasion of drilling-in fluids will cause severe permeability damage to the fractured system. The fractures near the wellbore can be filled by mud and the permeability reduction is very difficult to reverse during flow back. Utilizing the sized bridging agents, such as $\mathrm{CaCO}_{3}$ and fiber materials according to the ideal packing technique is very effective to prevent the solids or filtrate from invading into the fractured formation.

5) The experimental results show that the feasibility of the new evaluation method, which can be used to optimize the sized temporary sealing design. The new evaluation method can also be used to evaluate the effectiveness of sealing which is achieved by adding the temporary sealing particles in the drill-in fluid. The sealing cake can be observed obviously on the edge of the stainless steel simulated core in the evaluation tests after adding sized ideal-packing bridging agent into the drill-in fluid.

\section{Acknowledgments}

The authors thank the Committee of National Natural Science Foundation for providing financial support for this research project (Project No. 50574061). We also appreciate the support provided by the Changjiang Scholars and Innovative Research Team (No. IRT0411), Ministry of Education, People's
Republic of China.

\section{References}

Al-Taq A, Bazin B and Egermann P. Mud-induced formation damage in carbonate reservoirs: Consequences on productivity of open-hole horizontal wells. SPE European Formation Damage Conference held in Sheveningen, the Netherland, 25-27 May, 2005 (SPE paper 94551)

Bailey M and Boek E. Particulate invasion from drilling fluids. SPE European Formation Damage Conference held in the Hague, the Netherlands, 31 May-1 June, 1999 (SPE paper 54762)

Chauveteau G, Nabzar L and Coste J P. Physics and modeling of permeability damage induced by particle deposition. SPE Formation Damage Control Conference held in Lafayette, Louisiana, 18-19 February, 1997 (SPE paper 39463)

Cui Y C and Zhang Y. The research situation and development of formation damage and protect technology. Exploration Engineering. 1999. 43(Suppl.): 39-43 (in Chinese)

Di J and Sharma M. Mud-induced formation damage in fractured reservoirs. SPE Drilling \& Completion. 1996. 11(1): 11-16 (SPE paper 30107)

Feng W Q and Yan J N. Designing drill-in fluids by using ideal packing technique. Petroleum Science. 2007. 4(2): 44-51

Liu J, Kang Y L, Liu D W, et al. Research on the temporary shielding plugging experiment in considering fracture-pore reservoir of fracture width and pressure difference. Drilling and Production Technology. 2006. 29(2): 97-98, 101 (in Chinese)

Salimi S and Alikarami R. Mechanism of fluid invasion in naturally fractured reservoirs: Experimental study. International Symposium and Exhibition on Formation Damage Control held in Lafayette, Louisiana U.S.A, 15-17 February, 2006 (SPE paper 98292)

Yan J N. Technology of Drilling Fluids. Shandong: China University of Petroleum Press. 2001. 392-394 (in Chinese)

Yan J N and Feng W Q. Design of drill-in fluids for optimizing selection of bridging particles. International Oil \& Gas Conference and Exhibition in China held in Beijing, China, 5-7 December, 2006 (SPE paper 104131)

Zheng Y L, Zhao D M, Hu G S, et al. The application of FMI in horizontal wells in carbonate reservoir. Xinjiang Geology. 2004. 22(3): 319-322 (in Chinese)

(Edited by Sun Yanhua) 